\title{
Evaluation of a Collagen Membrane With and Without Bone Grafts in Treating Periodontal Intrabony Defects
}

\author{
Chuan-Chuan Chen, * Hom-Lay Wang, ${ }^{\dagger}$ Frederic Smith, ${ }^{\dagger}$ Gerald N. Glickman, ${ }^{*} Y u$
} Shyr, ${ }^{\S}$ and Robert B. O'Neal"

THE AIM OF THIS STUDY was to compare the clinical regenerative capacity of collagen membrane with and without demineralized freeze-dried bone allografts (DFDBA) in treating periodontal intrabony defects. Ten systemically healthy patients with similar bilateral periodontal defects were scheduled for surgery. Each patient had at least $\geq$ $6 \mathrm{~mm}$ clinical probing depth and loss of attachment at selected sites. Baseline measurements included gingival index (GI), plaque index (PI), gingival recession (GR), clinical attachment level (CAL), probing depth (PD), and mobility. At the time of surgery, the defects were randomly assigned to either test (collagen membrane plus DFDBA) or control group (collagen membrane only). Stent to base of the defects, stent to crest bone, crest of bone to base of the defect, and width of the defects were recorded at the time of surgery and reentry. Eight patients returned after 6 months for reentry surgery. Statistical analysis with a paired $t$ test was used to evaluate the treatment effect and comparison between test and control groups. In addition, a McNemar test was used to analyze the significance of GI, PI, and mobility at different times. The result of this study indicated that both the collagen plus DFDBA and the collagen alone treatment groups had a significant decrease of PD $(3.4 \pm 0.4$ and $3.2 \pm 0.4 \mathrm{~mm})$, gain of CAL $(2.3 \pm 0.5$ and $2.0 \pm 0.4 \mathrm{~mm})$, and defect fill $(1.7 \pm 0.3$ and $1.9 \pm 0.9 \mathrm{~mm})$ $(P<0.05)$ when compared to the presurgery status. However, there was no significant difference in PD, AL, GR, defect fill, crestal bone resorption, GI, PI, or mobility between the test group and control group. No adverse tissue reaction, infection, or delayed wound healing was noted throughout the treatment in either group. This study suggests that the collagen membrane is well tolerated by the human tissues. Both treatments, either collagen membrane plus DFDBA or collagen membrane alone, promoted significant resolution of periodontal intrabony defects. The addition of a bone graft (DFDBA) with a collagen membrane appears to add no extra benefit to the collagen membrane treatment. J Periodontol 1995;66:838-847.

Key Words: Collagen/therapeutic use; guided tissue regeneration; bone, grafts; bone, freeze-dried; periodontal diseases/therapy; membranes, barrier; membranes, artificial.

Connective tissue cells in gingival corium, periodontal ligament, cementum, and bone represent different phenotypes and it is the phenotype of the cells repopulating

\footnotetext{
*Private practice, Taipei, Taiwan.

tDepartment of Periodontics/Prevention/Geriatrics, School of Dentistry, University of Michigan, Ann Arbor, MI.

*Department of Cariology, Restorative Sciences, and Endodontics.

${ }^{\$}$ Division of Biostatistics, Department of Preventive Medicine, School of Medicine, Vanderbilt University, Nashville, TN.

"Currently, Department of Periodontology, School of Dentistry, University of Washington, Seattle; previously, Department of Periodontics/Prevention/Geriatrics, University of Michigan.
}

an area after wounding that determined the character of the regenerative response. ${ }^{1}$ Studies in animals and humans, using either expanded polytetrafluoroethylene $(\mathrm{ePFTE})^{\mathrm{I}}$ membranes or Millipore ${ }^{\#}$ filters, resulted in the formation of more new attachment when compared to controls both clinically and histologically. ${ }^{2-4}$ However, a second surgical procedure to remove the membrane is an additional burden to both clinician and patient. Efforts are being directed to developing a barrier membrane which

\footnotetext{
"W.L. Gore and Associates, Flagstaff, AZ.
} "Millipore SA, Molsheim, France. 
is fully absorbable, such as a processed bovine collagen membrane. The absorbable collagen membrane can act as a barrier analogous to a nonabsorbable membrane and it is either incorporated into the healing connective tissues or is degraded by macrophages in 6 to 8 weeks. Exogenous collagen is chemotactic for periodontal ligament fibroblasts and also improves fibroblast migration and attachment through its scaffold-like fibrillar structure. ${ }^{5}$ It also creates a thrombogenic surface that stimulates platelet attachment which may accelerate fibrin and clot attachment. ${ }^{6}$ These biological properties of collagen may aid in periodontal reconstructive procedures. Numerous studies have proven the effectiveness of using collagen membranes in guided tissue regeneration (GTR) therapy. ${ }^{7-13}$ A previous study has demonsträted that sites treated with a collagen barrier exhibited a statistically significant higher bone fill and improvement of furcation horizontal bone repair and defect improvement than the sites treated without a collagen barrier. ${ }^{14}$

The effect of combining a bone graft with GTR material has been evaluated. ${ }^{15-17}$ Anderegg et al. ${ }^{15}$ used freeze-dried bone allograft in promoting regeneration of Class II furcation involvements. In sites treated with bone grafts, formation of new cementum and connective tissue attachment was observed. However, no evidence of new bone formation was reported in the group without using bone grafts. When porous hydroxyapatite was used in conjunction with an ePTFE membrane, less gingival recession and more defect fill were obtained. ${ }^{16}$ Apposition of alveolar bone was noted in dehiscence and horizontal defects when osseous composite grafting, root conditioning with citric acid, and membrane were used together as compared to the membrane only treated sites. ${ }^{17}$ When collagen gel was combined with bony grafts in a $1: 1$ ratio by volume in treating periodontal intrabony defects in dogs, Blumenthal and coworkers noticed that it offered advantages over the bone graft alone. ${ }^{18}$ Nery and colleagues found the use of combined biphasic calcium phosphate ceramic and fibrillar collagen to be beneficial in promoting new attachment of periodontal tissues to the tooth root surfaces in dogs. ${ }^{19}$ In addition, a positive result was reported in the sites treated with supracrestal tricalcium phosphate ceramic and collagen grafts when compared to the collagen grafts control sites in a human study. ${ }^{20}$ Other studies have also shown that collagen membranes combined with bone grafts are effective in treating intrabony defects. ${ }^{21-22}$ On the contrary, Caffesse et al. found that GTR procedures resulted in an increase in connective tissue and alveolar bone regeneration, but adjunctive bone grafting did not appear to enhance regeneration. ${ }^{23}$ In promoting bone formation around immediate dental implants, the addition of DFDBA to ePTFE membrane was questioned as a method to regenerate bone. ${ }^{24}$ Due to these conflicting reports in the literature, it is the aim of this study to compare the clinical regenerative abil- ity of intrabony defects treated with collagen membranes either with or without bone grafts.

\section{MATERIAL AND METHODS}

\section{Patient Selection}

This research is an expansion of an ongoing absorbable collagen membrane clinical trial in the Department of Graduate Periodontics at The University of Michigan, School of Dentistry. The protocol was approved by the Human Subject Review Committee at The University of Michigan for clinical use. Ten systemically healthy patients, 6 males and 4 female, aged from 26 to 62 , were included in this study. Patients entered the study either directly after a standard preparation stage (i.e., oral hygiene instruction, scaling and root planing, and other initial disease control procedures) or upon the decision that surgical intervention was needed during maintenance therapy. The following criteria were used to select the subjects for this clinical study: 1) evidence of moderate or advanced periodontitis; 2) similar intraosseous defects exhibiting attachment loss $\geq 6 \mathrm{~mm}$ and probing depths $\geq 6 \mathrm{~mm}$; 3) radiographic evidence of intrabony vertical defect; 4) no antibiotic therapy in the past 6 months; and 5) no periodontal surgery within the last 12 months. Informed consents from all patients who met the criteria and agreed to participate in the study were obtained.

\section{Measurements}

Clinical data included probing depths (PD) of the periodontal defects; clinical attachment levels (CAL); gingival recession (GR); mobility; and plaque (PI) and gingival (GI) indices were collected at baseline (at the time of the surgery) and at 1,2,3, and 4 weeks and 6 months after surgery. An acrylic resin surgical stent was made for each patient. Measurements were taken from this surgical stent with a ledge and vertical grooves (Fig. 1) pre- and postsurgically. PD were obtained using a North Carolina 15 $\mathrm{mm}$ probe: the deepest point at defect site from the stent vertical groove of selected tooth was recorded. CAL was obtained from reference points (surgical stent) to the base of the periodontal defect by using an automated probe** to reduce any measuring errors. GR was measured from the stent to the free gingival margin on the defect site. Tooth mobility was detected utilizing Miller's classification $(0=$ no mobility; $1=$ the first distinguishable sign of movement greater than normal; $2=$ movement of 1 $\mathrm{mm}$ from normal position in any direction; and $3=$ movement of more than $1 \mathrm{~mm}$ in any direction). ${ }^{25}$ PI was recorded according to Silness and Löe. ${ }^{26}$ GI was measured using the criteria described by Löe and Silness. ${ }^{27}$ The following measurements were taken: stent to the base of defect (SB), crest of bone to base of defect (CB), and bucco-

**Florida Probe Co., Gainesville, FL. 


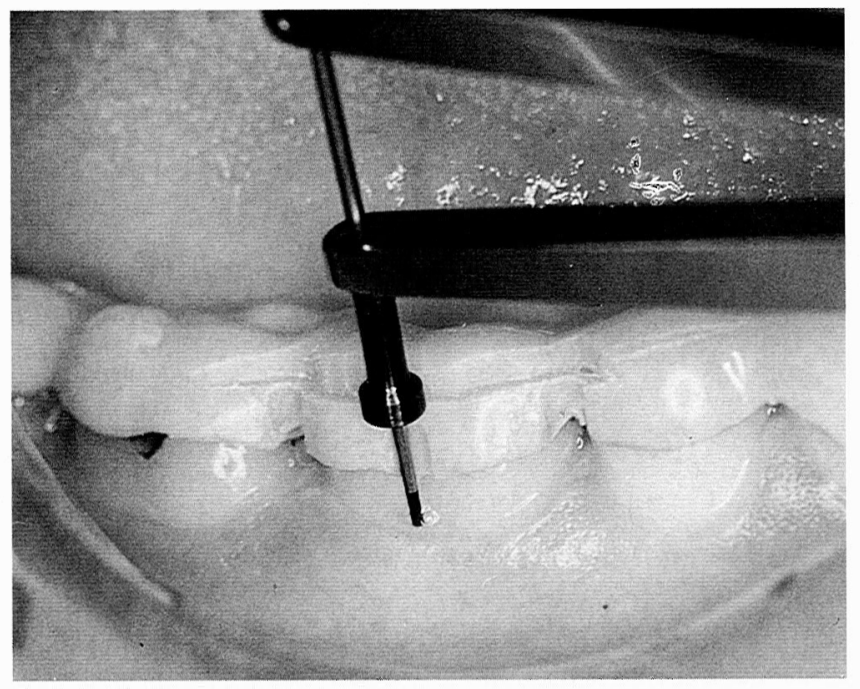

Figure 1. Demonstrates how the clinical measurements were taken from the surgical stent ledge and grooves.

lingual/mesio-distal morphology of the intrabony defects, at the time of surgery, and at 6 months re-entry surgery.

\section{Surgical Protocol}

All surgical procedures were carried out from February 1993 to July 1994 in the surgery clinic of Graduate Periodontics at The University of Michigan, School of Dentistry. Defects were randomly assigned (by flipping a coin) to treatment of using collagen membranes either with or without demineralized freeze-dried bone allografts (DFDBA). ${ }^{\dagger \dagger}$ Following adequate local anesthesia, internal beveled incisions were made buccally and lingually in the test and control sites with the intention to preserve the interdental papilla. The defects were debrided and all root surfaces were completely scaled and root planed by ultrasonic, hand instrumentation, and rotary burs to a smooth and hard consistency. Minor osteoplasty without removal of any supporting bone was performed to facilitate proper flap adaptation. Absorbable collagen membranes ${ }^{\ddagger \ddagger}$ (prepared from purified bovine Achilles tendon in a chemically cross-linked form and supplied in individual $18 \mathrm{~mm} \times 38 \mathrm{~mm} \times 0.15$ to $0.22 \mathrm{~mm}$ sterile pieces) were cut, fitted, and placed over the defects on both test and control sides. The membrane was sutured with 5-0 chromic gut sutures if it did not sit uniformly over the osseous defect, otherwise no suture was used. In the test group, a DFDBA bone graft implant material was prepared in a sterile dappen dish to a paste-like consistency and was implanted into the intrabony defects with intention of slightly overfilling. The flap was subsequently sutured into its original position with 4-0 black silk sutures. On the control side, all surgical procedures were identical

\footnotetext{
${ }^{\dagger}$ LifeNet, Virginia Beach, VA.
}

*\#Biòed, Calcitek, Inc., Carlsbad, CA. except that no bone graft was placed. The surgical procedure of placing collagen membrane is shown in Figure 2. Patients then received routine written and oral postoperative instructions. All the patients were prescribed with doxycycline $100 \mathrm{mg} /$ day for 2 weeks and were also instructed to rinse with $0.12 \%$ chlorhexidine gluconate for a period of 4 weeks. The 4-0 silk sutures were removed one week after the surgery. Patients returned weekly for 4 weeks for observation of any adverse tissue reactions. Patients were then seen at 2, 4, and 6 months postsurgery for tissue evaluation, plaque debridement, and oral hygiene review.

\section{Six Months Re-Entry Surgery}

At the end of 6 months, the patients were scheduled for re-entry surgery. Clinical measurements (GI, PI, PD, $\mathrm{CAL}$, stent to the free gingival margin, and mobility) of the involved tooth were recorded prior to the surgery. Surgical re-entry consisted of sulcular incisions to preserve attached gingiva and interdental papillae. Fullthickness mucoperiosteal flaps were designed to expose the previously treated defect areas for clinical photographs and measurements as previously described. Flaps were then replaced and sutured. Patients were seen at 1 week postsurgery for suture removal, and then placed on a closely supervised 3-month schedule for supportive periodontal treatment.

\section{Statistical Analysis}

The data were organized and presented as means \pm standard error and analyzed using the SAS system. $\$$ The McNemar test and the paired $t$ test were utilized to determine the significance of changes over time and clinical parameters with respect to treatment modality. Significance was reported at the 95\% confidence level ( $\alpha=$ 0.05 ). Under $\alpha=0.05$ statistical power set at 0.80 , eight patients are needed to show a statistically significant difference between treatments with a change in CAL of 1 $\mathrm{mm}$ and a standard deviation set at 0.5. However, if the standard deviation is set at 0.8 , then the number should be increased to 14 to indicate the difference.

\section{RESULTS}

Ten patients, 4 females and 6 males with an age range of 26 to 62 (mean age, 38.2) years old, participated in this study. Of the 20 teeth selected, one site did not qualify for the research at the time of surgery. Therefore 10 teeth were treated with flap surgery followed by a combination of DFDBA and collagen membrane, whereas the remaining 9 teeth were treated with the same flap surgery but without bone grafts (collagen membrane only). Patients were seen at baseline, 1, 2, 3, 4, 8, and 12 weeks and reentry surgery was performed from 6 to 12 months after

${ }^{\$}$ SAS Institute, 6.04 SAS, Cary, NC. 


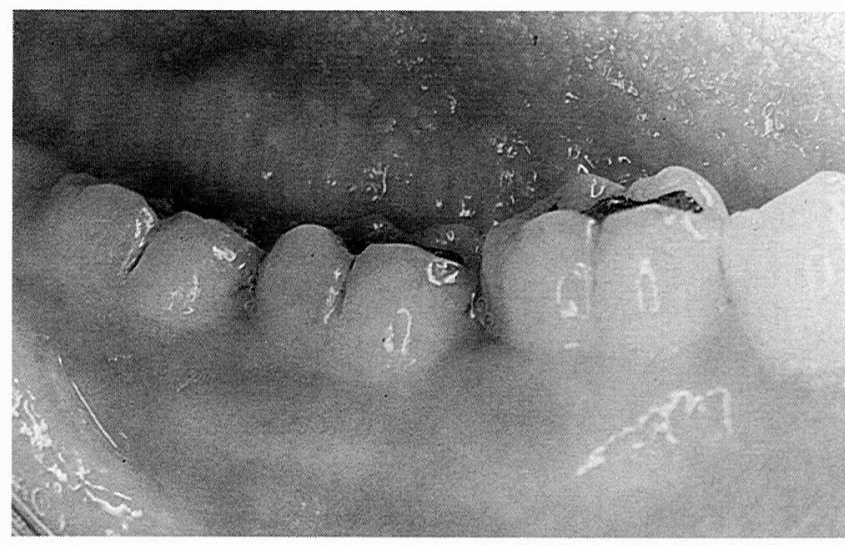

Figure 2. Surgical procedures for Patient 1. All photographs represent a mirror image. 2A. Presurgery status.

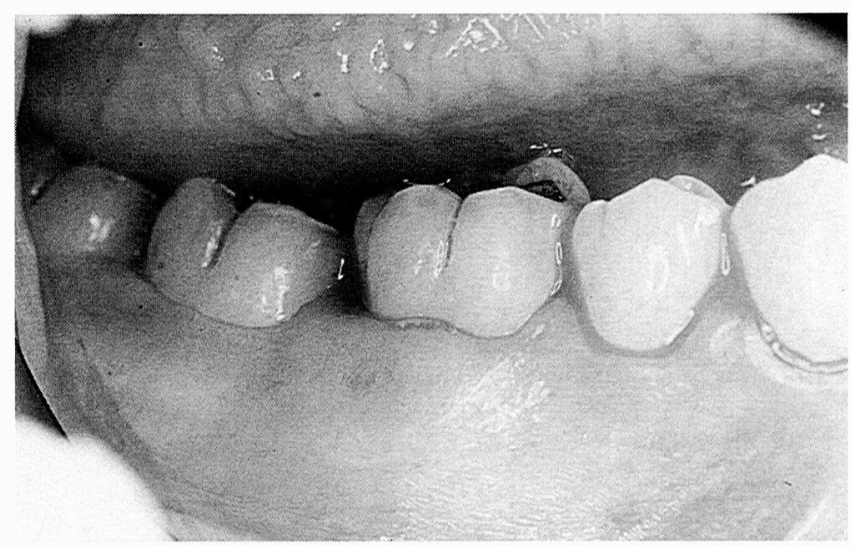

2B. Sulcular incision made in order to preserve all the interdental papillae.

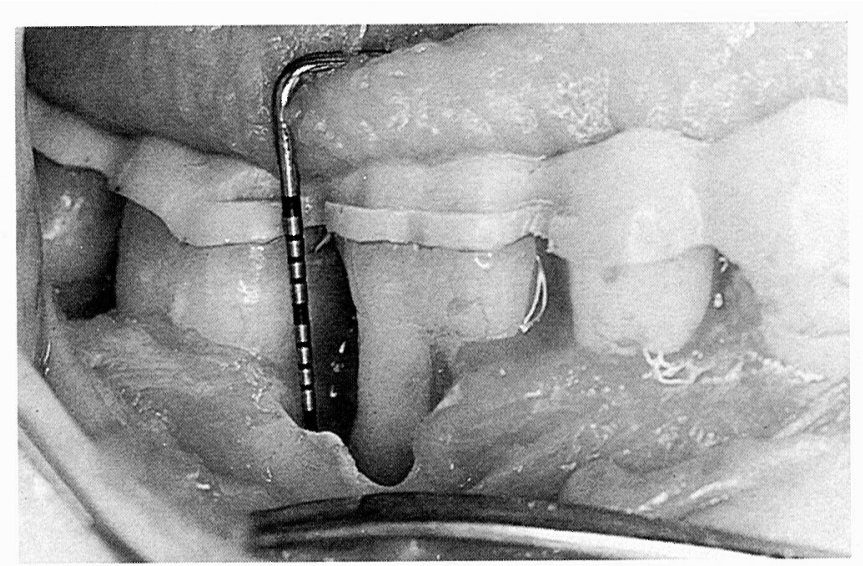

2C. Defects debrided and measurements made from the stent.

surgery. Two patients did not return for re-entry surgery: one moved away and the other refused to have re-entry surgery. Hence only 8 patients had re-entry surgery ( 2 at 6 months; 5 at 7 months; and 1 at 12 months). Clinical and radiographic comparisons, both presurgically and postsurgically, are shown in Figures 2 and 3. Patient demographic information is shown in Table 1.

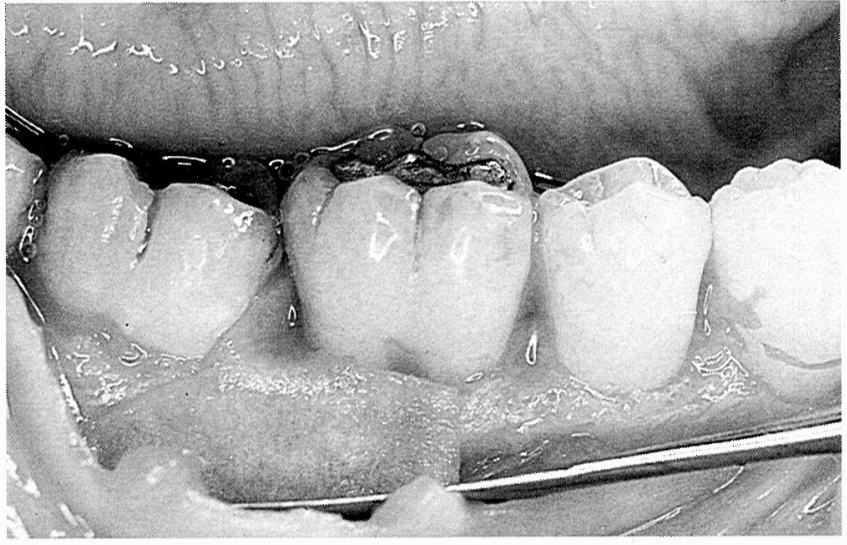

2D. Membrane was placed over the defect without suturing.

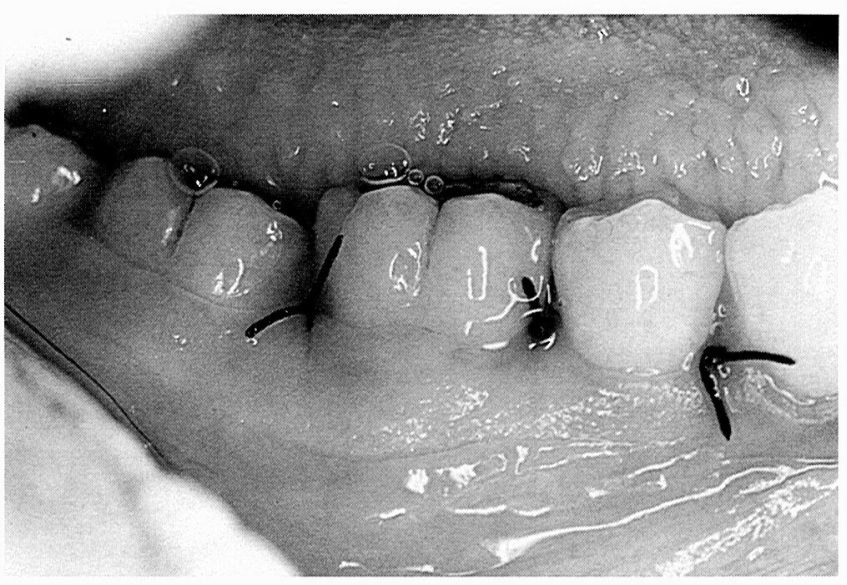

2E. Flap positioned coronally and primary coverage achieved over the membrane.

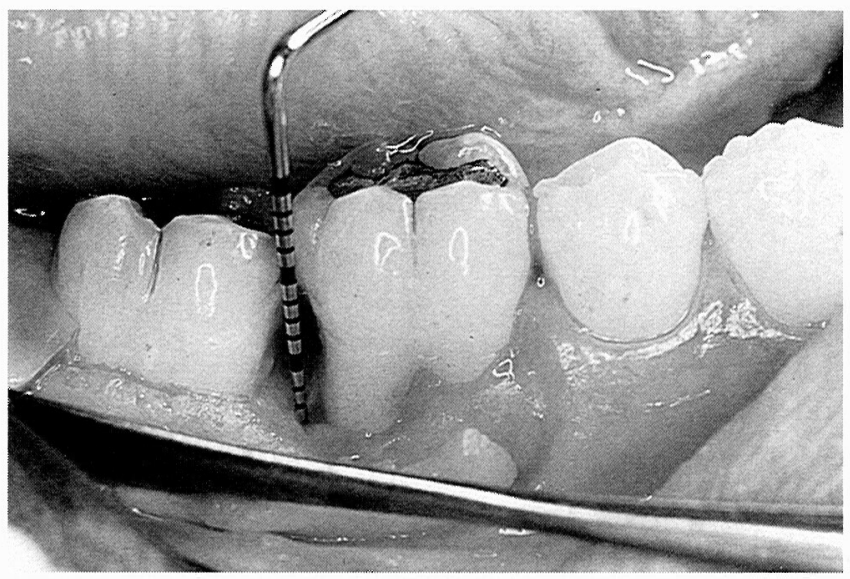

2F. Re-entry surgery showing the new bone formation with probe in place.

During the course of this study, no adverse tissue reaction, infections, or delayed healing were reported. As demonstrated in Table 2, there were no significant changes in GI, PI, and mobility in either test or control sites between baseline; 1, 2, and 4 weeks; and upon reentry surgery. 


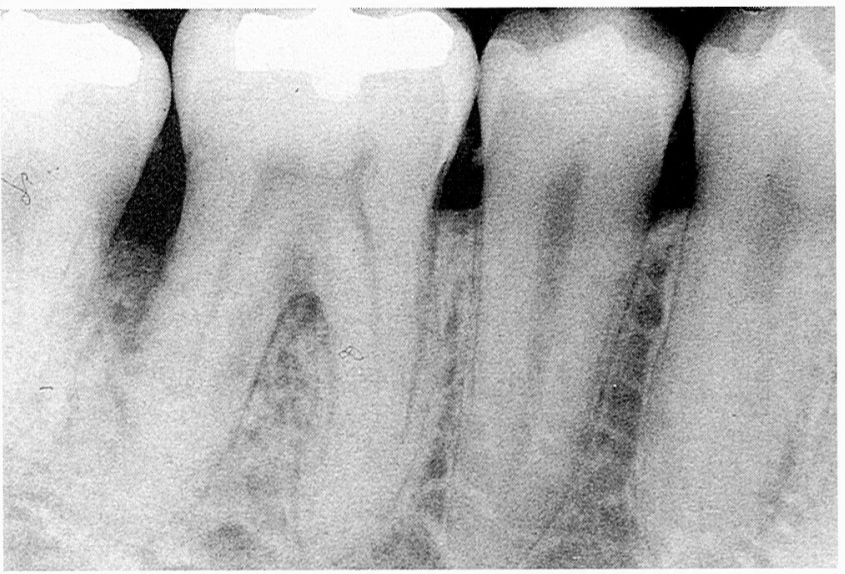

Figure 2 (continued) 2G. Presurgical periapical radiograph.

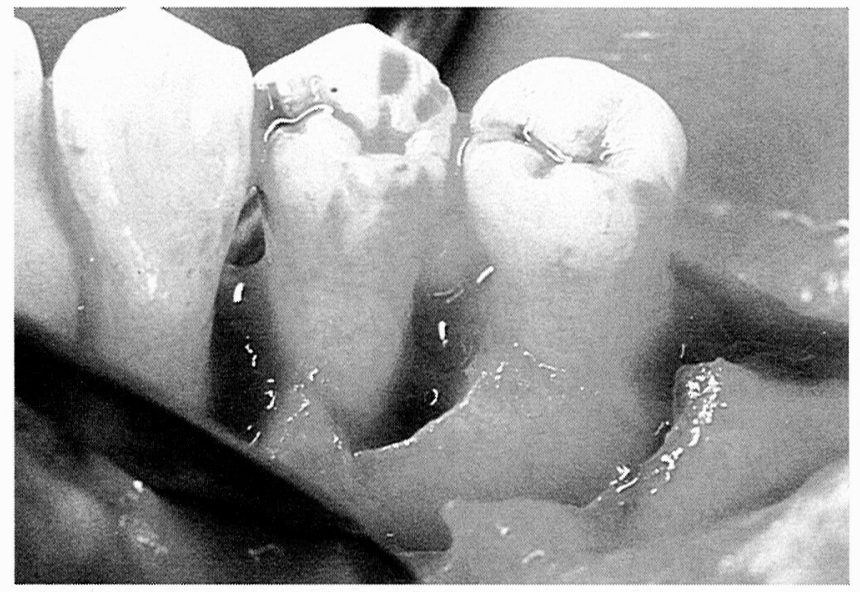

Figure 3. Patient 5 Collagen + DFDBA (\#28) and collagen only treated sites (\#27). All photographs represent a mirror image. 3A. Initial defects.

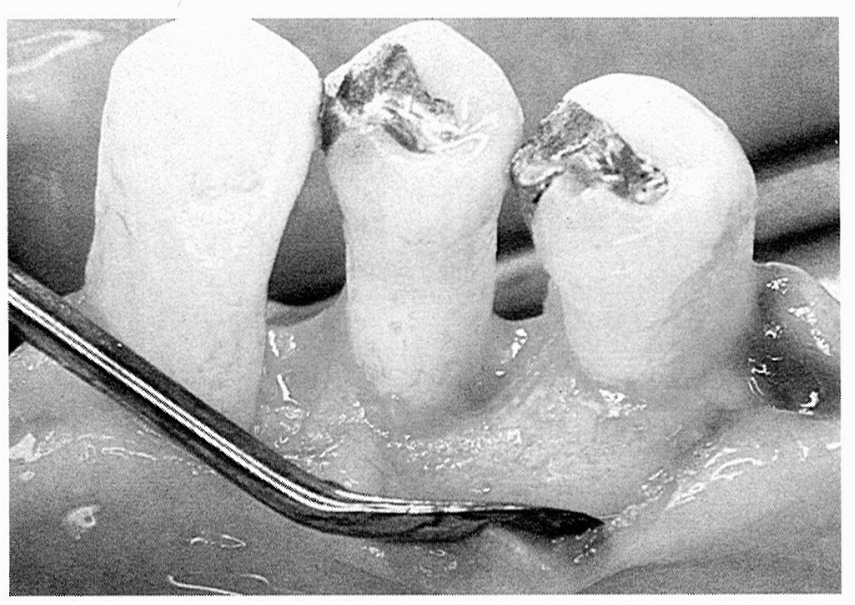

3B. Re-entry surgery showing the newly formed bone and dense tissues.

Table 3 represents the baseline and 6-month re-entry measurements, whereas Table 4 compares the difference between the treatment groups. No difference was noted on all soft tissue measurements (PD, CAL, and GR) at baseline and 6-month re-entry between collagen +

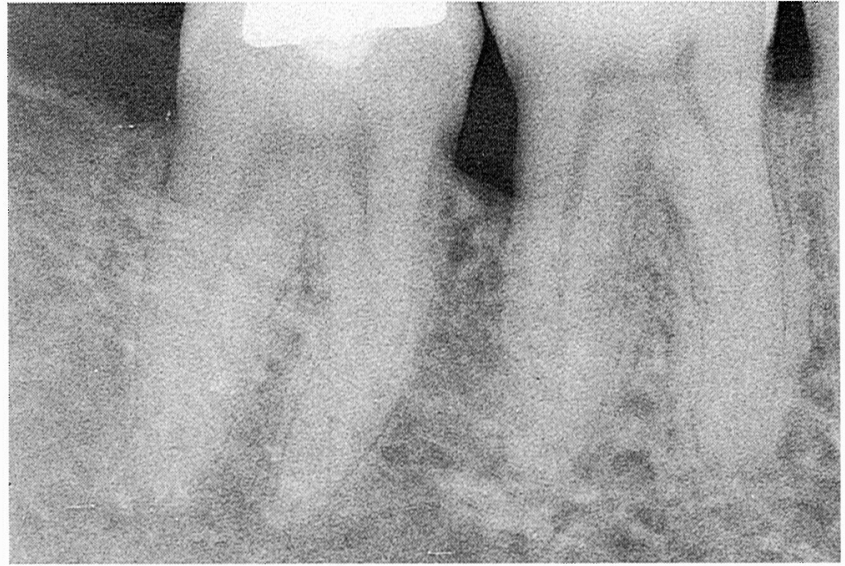

2H. Postsurgical periapical radiograph.

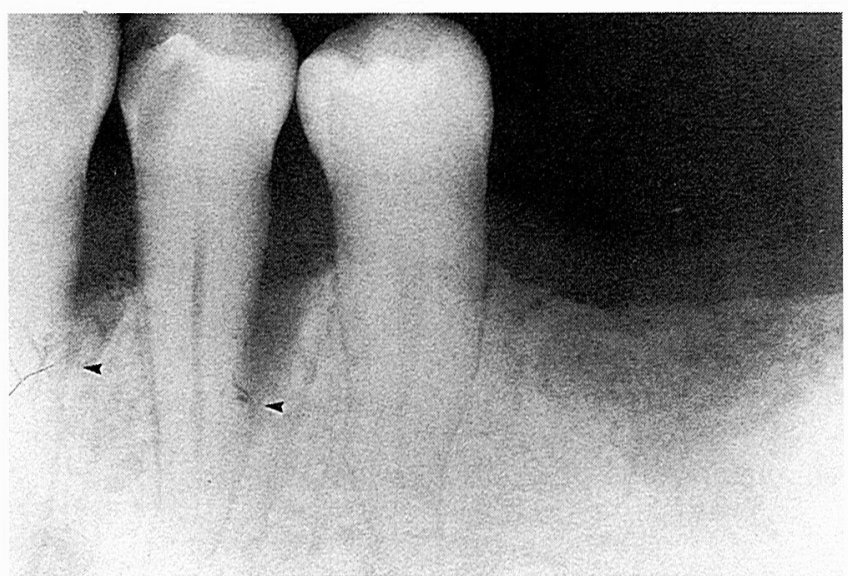

3C. Presurgical periapical radiograph.

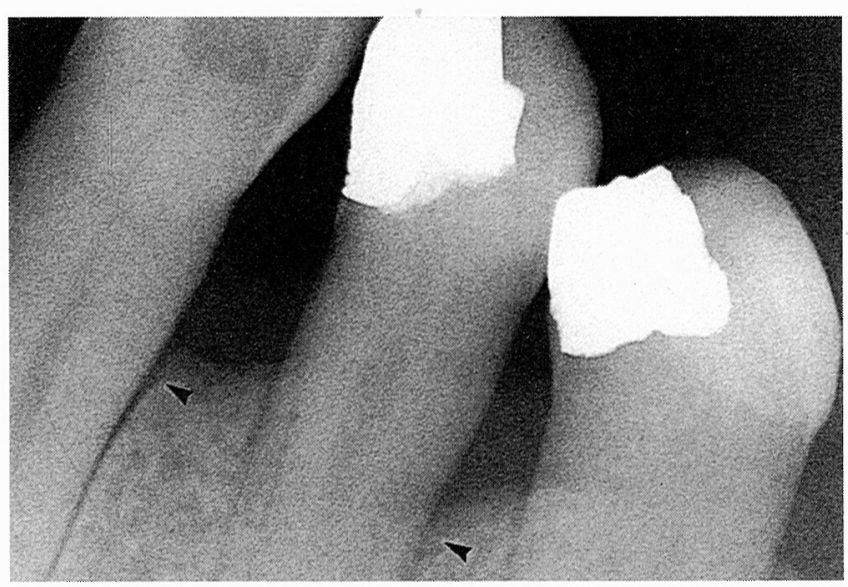

3D. Postsurgical periapical radiograph (arrows indicate the radiographic base of the defect).

DFDBA and collagen membrane treated sites. The mean PD improvement for the collagen + DFDBA treated defects was $3.4 \mathrm{~mm}$ as compared to $3.2 \mathrm{~mm}$ for the controls. When the 6-month re-entry values were compared to the baseline measurements, both treatment modalities showed significant reduction of PD from baseline. Collagen + 
Table 1. Demographic Information

\begin{tabular}{cccccc}
\hline Patient & Sex & Age & $\begin{array}{c}\text { Collagen } \\
\text { DFDBA } \\
\text { Tooth }\end{array}$ & $\begin{array}{c}\text { Collagen } \\
\text { Tooth }\end{array}$ & $\begin{array}{c}\text { Re-entry } \\
\text { time } \\
\text { (months) }\end{array}$ \\
\hline 1 & M & 31 & - & 19 & 12 \\
2 & M & 41 & 14 & 3 & 6 \\
3 & F & 35 & 30 & 19 & 7 \\
4 & M & 41 & 19 & 30 & 7 \\
5 & M & 62 & 28 & 27 & 7 \\
6 & M & 43 & 2 & 15 & 7 \\
7 & F & 33 & 19 & 31 & 6 \\
8 & F & 35 & 31 & 18 & 7 \\
9 & F & 26 & 19 & 31 & no \\
10 & M & 35 & 4 & 13 & no \\
\hline
\end{tabular}

DFDBA and collagen membrane treated sites showed a statistically significant gain of CAL $(2.3 \mathrm{~mm}$ and $2.0 \mathrm{~mm}$, respectively) when compared to the presurgery status. Paired $t$ test indicated that the gain of CAL was not significantly different between two groups, but the test group had a slight tendency to gain more CAL than the control group. No difference was noted between test and control sites with regards to GR, either pre- or postsurgically.

Hard tissue measurements including SB, CB, and width of the defects, both bucco-lingual and mesio-distal, were recorded during the surgery. The differences of SB between baseline and re-entry represent the amount of vertical bone defect fill. The collagen + DFDBA and collagen barrier treated sites showed significant improvements in defect fill $(P<0.01)$ as compared to the presurgery status. However, no statistically significant difference was noted between the two groups $(1.7 \pm 0.3$ $\mathrm{mm}$ vs. $1.9 \pm 0.9 \mathrm{~mm}$ ). Table 5 indicates that 3 out of 7 sites treated with collagen + DFDBA had more than 50\% of defect fill as compared to 5 out of 8 sites in membrane treated control group. No difference was found in CB between test and control sites at 6 months re-entry.

The crestal bone resorption was obtained from the difference of stent to crest of bone between baseline and 6 months. The amount of crestal bone resorption was similar in both collagen + DFDBA and collagen membrane treated sites $(0.7 \mathrm{~mm}$ vs. $0.5 \mathrm{~mm})$; there was no statistically significant difference between the two groups. When considering the bucco-lingual width measurements, both treated groups showed an improvement $(1.8 \mathrm{~mm}$ for the collagen group and $1.4 \mathrm{~mm}$ for the collagen + DFDBA) when compared to the baseline; however, no statistically
Table 3. Clinical Measurements for Collagen + DFDBA and Collagen (control) Groups at Baseline and Re-entry $(n=7$ in collagen + DFDBA group; $n=8$ in collagen group)

\begin{tabular}{lrrrrr}
\hline & \multicolumn{2}{c}{ Collagen + DFDBA } & & \multicolumn{2}{c}{ Collagen } \\
\cline { 2 - 3 } \cline { 5 - 6 } Measurements & Baseline & Re-entry & & Baseline & Re-entry \\
\hline Soft tissue & & & & \\
$\quad$ Probing depth & $7.6 \pm 0.4$ & $4.2 \pm 0.5$ & $7.4 \pm 0.4$ & $4.2 \pm 0.4$ \\
$\quad$ Attachment level & $11.1 \pm 0.6$ & $8.8 \pm 0.8$ & $11.1 \pm 0.5$ & $9.1 \pm 0.8$ \\
$\quad$ Gingival recession & $3.7 \pm 0.4$ & $4.7 \pm 0.4$ & $4.1 \pm 0.5$ & $5.4 \pm 0.5$ \\
Hard tissue & & & & \\
$\quad$ Stent to base of defect & $12.5 \pm 0.6$ & $10.8 \pm 0.8$ & $13.2 \pm 0.7$ & $11.3 \pm 1.0$ \\
$\quad$ Stent to crest of bone & $7.7 \pm 0.4$ & $8.4 \pm 0.5$ & $8.4 \pm 0.5$ & $8.9 \pm 1.0$ \\
\hline
\end{tabular}

Table 4. Clinical Changes at 6-Month Re-entry $(n=7$ in collagen + DFDBA group; $n=8$ in collagen group)

\begin{tabular}{lccr}
\hline & $\begin{array}{c}\text { Collagen }+ \\
\text { DFDBA } \\
\text { Measurements }\end{array}$ & $\begin{array}{c}\text { Collagen } \\
\text { (mean } \pm \text { SE) } \\
\text { (mean } \pm \mathrm{SE})\end{array}$ & Difference \\
\hline Soft tissue & & & \\
$\quad$ Probing depth & $3.4 \pm 0.4^{*}$ & $3.2 \pm 0.4^{*}$ & $0.2 \pm 0.5$ \\
$\quad$ Attachment level & $2.3 \pm 0.5^{*}$ & $2.0 \pm 0.4^{*}$ & $0.3 \pm 0.8$ \\
$\quad$ Gingival recession & $1.0 \pm 0.4^{*}$ & $1.3 \pm 0.4^{*}$ & $-0.3 \pm 0.4$ \\
Hard tissue & & & \\
$\quad$ Defect fill & $1.7 \pm 0.3^{*}$ & $1.9 \pm 0.9^{*}$ & $-0.2 \pm 1.0$ \\
$\quad$ Crestal bone resorption & $0.7 \pm 0.2^{*}$ & $0.5 \pm 0.8$ & $0.2 \pm 0.9$ \\
\hline
\end{tabular}

*Statistically significant difference from the baseline.

No statistically significant differences were found between the two treatment groups.

Table 5. Percentage of Defect Fill after 6 Months ( $n=7$ in collagen + DFDBA group and $n=8$ in collagen group)

\begin{tabular}{lcccc}
\hline Group & None & $0-25 \%$ & $25-50 \%$ & $>50 \%$ \\
\hline Collagen + DFDBA & 1 & 0 & 3 & 3 \\
Collagen & 2 & 0 & 1 & 5 \\
\hline
\end{tabular}

significant difference was noted between the two groups. A statistically significant reduction of mesio-distal width was noted in the collagen treated groups but not in the collagen + DFDBA treated groups. No difference was found between the two groups at baseline and re-entry.

\section{DISCUSSION}

Guided tissue regeneration (i.e., epithelial exclusion and selective repopulation of the root surface by multipoten-

Table 2. Comparison of Clinical Parameters Between Collagen + DFDBA and Collagen (control) (mean \pm standard error) at Different Time Periods $(n=8)$

\begin{tabular}{llccccc}
\hline Parameters & \multicolumn{1}{c}{ Group } & Baseline & 1 Week & 2 Weeks & 4 Weeks & 6 Months \\
\hline Gingival index & Collagen + DFDBA & $0.4 \pm 0.2$ & $0.7 \pm 0.2$ & $0.7 \pm 0.3$ & $0.6 \pm 0.2$ & $0.4 \pm 0.2$ \\
& Collagen & $0.6 \pm 0.4$ & $0.8 \pm 0.2$ & $0.8 \pm 0.2$ & $0.5 \pm 0.2$ & $0.4 \pm 0.2$ \\
Plaque index & Collagen + DFDBA & $0.3 \pm 0.2$ & $0.3 \pm 0.2$ & $0.3 \pm 0.2$ & $0.0 \pm 0.0$ & $0.4 \pm 0.1$ \\
& Collagen & $0.3 \pm 0.2$ & $0.3 \pm 0.2$ & $0.1 \pm 0.1$ & $0.1 \pm 0.1$ & $0.1 \pm 0.1$ \\
\hline
\end{tabular}

Nò statistically significant difference. 
tial cells) utilizing non-absorbable occlusive membranes (such as an ePTFE membrane) has become an accepted mode of therapy in periodontics. ${ }^{28,29}$ However, several drawbacks have been documented including the need for a second surgical procedure to retrieve the membrane which may disrupt healing and could create further bone and attachment loss. Clinical trials using absorbable collagen membranes have shown them also to be effective in treating periodontal defects. ${ }^{8,9,14}$ Collagen membranes have been used because collagen is the most abundant protein in the body and the main constituent of periodontal connective tissue. In addition, the collagen membrane has the following properties: it is a weak immunogen, ${ }^{30}$ it provides a scaffold for PDL cell migration, ${ }^{31}$ it is chemotactic for fibroblasts ${ }^{5}$ and it can be easily manipulated and adapted. These properties make it attractive for use in GTR procedures.

Results from this study reported no adverse tissue reaction, infections, or delayed healing. It was initially believed that an inflammatory reaction might occur following the implantation of the collagen material due to its non-human origin. However, the GI and PI were low at both test and control sites at all time periods during the experiment. This is in agreement with Blumenthal $^{8}$ and previous findings. ${ }^{14}$ These findings imply that the collagen membrane is a biocompatible and safe material for use in humans. Furthermore, Quteish et al., using light and electron microscopy to test the biocompatibility, resorption, and penetration characteristics of human collagen graft material, concluded that the inflammatory reaction occurring after the implantation of collagen is slight and will eventually resolve,,$^{31}$ as observed in this study.

Opinions on the effectiveness of DFDBA during GTR are varied. ${ }^{23,32}$ DFDBA has been used during GTR procedures because it is thought to be a space filler and to enhance periodontal tissue regeneration by its osteoinductive properties. ${ }^{32}$ McClain and Schallhorn have demonstrated that the long-term success of GTR is significantly enhanced by the addition of root conditioning and grafting procedures. ${ }^{33}$ Anderegg et al. also reported that the addition of bone grafts during the GTR procedure resulted in significantly more PD reduction than the membrane only group..$^{15}$ On the other hand, some groups feel that bone grafts during GTR may block cell migration and inhibit the regenerative potential. ${ }^{23}$ These results indicated that both treatments (collagen membrane with or without bone grafts) had significant effects on soft tissue measurements by reducing PD and gaining in CAL. However, there was no statistically significant gain in PD reduction or gain in CAL by adding bone grafts to collagen GTR procedures. Blumenthal and Steinberg used a combined graft of autolysed antigen-extracted allogenic bone and microfibrillar collagen with an absorbable collagen membrane in treating human intrabony defects. ${ }^{21}$ They found PD reduction similar to that observed in the present study. Variations in results between studies can be explained by many factors such as differences in the measuring techniques (stent vs. no stent, manual probe vs. automated probe), the nature and extent of the defects, and patient oral hygiene and compliance. Further studies are needed to clarify the true benefit of using DFDBA during GTR.

The amount of gingival recession found in the present study averaged 1.0 and $1.3 \mathrm{~mm}$ in both groups. This result is in agreement with most other GTR studies. ${ }^{14,21,34,35}$ Blumenthal and Steinberg reported a $0.96 \mathrm{~mm}$ of GR in collagen membrane treated sites and $0.91 \mathrm{~mm}$ in the combination therapy sites. ${ }^{21}$ Guillemin et al. demonstrated 0.9 mm of GR in sites treated with a bone graft combined with a collagen membrane. ${ }^{34}$ Furcation defects treated with ePTFE membrane alone had $1.3 \mathrm{~mm}$ of GR was reported by Becker; ${ }^{35}$ this amount of gingival recession is similar to that formed as a result of conventional flap surgery. In a previous study, the regenerative capacity of collagen membranes was evaluated by comparing it to the treatment effect of conventional flap surgery. ${ }^{14}$

Blumenthal has reported less GR at the sites treated with supracrestal tricalcium phosphate ceramic and collagen grafts than compared to the non-grafted sites. ${ }^{20} \mathrm{Le}-$ kovic et al. also showed that bone grafts reduced the incidence of gingival recession during GTR procedures. ${ }^{16}$ These findings are further supported by Anderegg et al. ${ }^{15}$ Different osseous defects used and different methods chosen to measure the GR may explain the variation in results reported.

Hard tissue measurements were taken after the flap was reflected and the defect was debrided completely. Some tough fiber-like tissue was noticed inside several residual defects at the 6-month re-entry surgery (Fig. 3). It was firmer and denser than regular granulation tissue and was difficult to remove and probe. The nature of this type of tissue needs to be further investigated histologically. The outcome of the present study demonstrated significant defect fill in both the test and control groups $(P<0.01)$ as compared to their presurgical status. However, no statistically significant difference was noted between the two groups $(1.7 \pm 0.3 \mathrm{~mm}$ vs. $1.9 \pm 0.9 \mathrm{~mm})$. The results of the present study differ from other studies. ${ }^{15,36}$ Anderegg et al. ${ }^{15}$ and Wallace et al. ${ }^{36}$ found more defect fill in the combined ePTFE membrane and bone graft group than in the membrane only group when treating furcation defects. In addition, treatment of intraosseous defects by combining an ePTFE membrane and bone graft can produce greater defect fill than with bone grafts alone $(1.9 \mathrm{~mm}$ vs. $2.2 \mathrm{~mm}) .^{32}$ By using a collagen membrane instead of an ePTFE membrane to treat intraosseous defects, Blumenthal and Steinberg obtained greater defect fill in a combination therapy group than in a membrane group (3.71 $\mathrm{mm}$ vs. $1.83 \mathrm{~mm}) .{ }^{21}$ When freeze-dried bone allografts 
were combined with polyglactin 910 membranes $\|$ to treat periodontal defects, more bone formation occurred at the grafted sites than at the sites treated without bone grafts. ${ }^{37,38}$ These studies may agree with Urist et al., ${ }^{31}$ who reported that demineralized bone grafts greatly enhance osteogenic potential by providing a source of bone morphogenic protein which stimulates bone formation by osteoinduction. However, Caffesse et al. found that adjunctive bone grafting (xenograft) did not appear to enhance regeneration when using ePTFE in treating furcation defects in dogs..$^{23}$ Similar results have also been reported in immediate implant placement; the addition of DFDBA (xenograft) to ePTFE membrane did not add any additional benefit to the membrane. ${ }^{24} \mathrm{~A}$ recent study by Becker et al. has also questioned the use of DFDBA as a bone inductive graft material in extraction sockets in humans. ${ }^{39}$ These studies, including the present study, may indicate that the quantity of bone morphogenic protein in grafts (either homograft or xenograft) is insufficient to influence the clinical outcome, as reported by Rummelhart et al. ${ }^{40}$

The percentage of defect fill in the present study was $41 \%$ in the test group (collagen + DFDBA) and $38 \%$ in the control group (collagen only). The result was a little less than that found in the other regeneration studies. ${ }^{34,41,42}$ For example, the percentage of defect fill in intraosseous defects in the Guillemin study was $58 \%$ in the control group (DFDBA only) and $71 \%$ in the test group (ePTFE + DFDBA). ${ }^{34}$ This can be explained by the fact that "open probing new attachment" was used to evaluate the defect fill within furcation areas, a technique conducted by most investigators. ${ }^{35}$ This method measures both soft or hard tissues around the original defect after the flap is reflected at reentry surgery. Therefore, when "open probing new attachment" is used in evaluating the defect fill, the results should be better, since the measurement was taken from the new soft tissue instead of from the hard tissue. In contrast, this study measured only newly formed hard tissue (i.e., defects were completely debrided before the measurement was taken).

The crestal bone resorption was not significantly different between the test and control groups in this study. The mean crestal bone resorption was greater in the present study than other studies. ${ }^{15,21}$ It averaged 0.1 to 0.25 $\mathrm{mm}$ in those studies but was 0.5 to $0.7 \mathrm{~mm}$ in the present study. Our data seem to be in agreement with the previous study by Wood et al., who has reported a mean reduction of alveolar crest height of $0.62 \mathrm{~mm}$ after elevation of a full-thickness flap. ${ }^{43}$

The other two components of an intrabony defect are bucco-lingual and mesio-distal. Unlike the vertical component mentioned earlier, there was no significant defect fill in these two dimensions except in one group. A significant mesio-distal defect fill $(0.8 \pm 0.2 \mathrm{~mm})$ was ob-

IIVìicryl, Johnson \& Johnson Consumer Products, Skillman, NJ. served postsurgically in the control group $(P<0.01)$. Very few studies use this parameter due to the difficulty of obtaining proper measurements. A defect extending from the interproximal area to the line angle makes defect measurement complicated.

Previous GTR investigations have primarily concentrated on dehiscence and furcation lesions in animal studies and furcation lesions in human trials. ${ }^{3.35,44,45}$ Very few studies have evaluated the treatment of intraosseous defects with guided tissue regeneration, which account for most of the periodontal defects. In fact, interproximal defects offer different therapeutic challenges which are not experienced with furcation defects. ${ }^{34}$ Firstly, the morphology of an interproximal defect is difficult to access before the surgery. Secondly, it is difficult to perform adequate debridement because the width of the vertical defect is often insufficient to allow entry of an instrument to the base of the defect. Thirdly, proper placement of the membrane over the interproximal defect and complete coverage of the membrane with the flaps is technically demanding.

Limitations of this study include small sample size, short study period, and lack of a negative control. A longer follow-up period (more than 12 months) and a larger sample size with an experimental design including flap surgery alone (negative) control, bone graft only (positive control), membrane only, and membrane combined with bone graft groups could be beneficial. Due to the nature of clinical trials and a number of other factors, these desired conditions were not feasible. A real difference between treatment groups may have existed if the sample size had been larger. Hence, further study with a larger sample size is needed. An additional incremental study is currently being conducted to answer some further questions.

From this limited study, the following conclusions can be drawn: 1) In treating intrabony periodontal defects, using either a collagen membrane or a collagen membrane in combination with a bone graft, resulted in a significant decrease of probing depth, gain of new attachment, and defect fill. 2) The addition of a bone graft (DFDBA) to a collagen membrane does not add additional benefit to the collagen membrane alone treatment. 3) Collagen membranes are well-tolerated by human tissues. 4) Further studies are required to clarify the osteogenic potential of DFDBA, especially when used in combination with barrier membranes.

\section{REFERENCES}

1. Melcher AH. On the repair potential of periodontal tissues. $J$ Periodontol 1976;47:256-260.

2. Aukhil I, Pettersson E, Suggs C. Guided tissue regeneration. An experimental procedure in beagle dogs. J Periodontol 1986;57:727334.

3. Gottlow J, Nyman S, Karring T, Lindhe J. New attachment forma- 
tion as the result of controlled tissue regeneration. $J$ Clin Periodontol 1984;11:494-503.

4. Gottlow J, Nyman S, Lindhe J, Karring T, Wennstrom J. New attachment formation in the human periodontium by guided tissue regeneration. Case reports. J Clin Periodontol 1986;13:604-616.

5. Postlethwaite AE, Seyer JM, Kang AH. Chemotactic attraction of human fibroblasts to type I, II, and III collagens and collagen-derived peptides. Proc Natl Acad Sci (USA) 1978;75:871-875.

6. Steinberg AD, LeBreton G, Willey R, Mukherjee S, Lipowski J. Extravascular clot formation and platelet activation on variously treated root surfaces. J Periodontol 1986;57:516-622.

7. Becker J, Neukam FW, Schliephake H. Restoration of the lateral sinus wall using a collagen type I membrane for guided tissue regeneration. Int J Oral Maxillofac Surg 1992;21:243-246.

8. Blumenthal $\mathrm{N}$. The use of collagen materials in bone grafted defects to enhance guided tissue regeneration. Ill Dent $J$ 1987;56:176-179.

9. Chung KM, Salkin LM, Stein MD, Freedman AL. Clinical evaluation of a biodegradable collagen membrane in guided tissue regeneration. J Periodontol 1990;61:732-736.

10. Pitaru S, Noff M, Grosskopf A, Moses O, Tal H, Savion N. Heparan sulfate and fibronectin improve the capacity of collagen barriers to prevent apical migration of the junctional epithelium. $J$ Periodontol 1991;62:598-601.

11. Pitaru S, Tal H, Soldinger M, Grosskopf A, Noff M. Partial regeneration of periodontal tissues using collagen barriers. Initial observations in the canine. $J$ Periodontol 1988;59:380-386.

12. Pitaru $\mathrm{S}$, Tal $H$, Soldinger M, Noff M. Collagen membranes prevent apical migration of epithelium and support new connective tissue attachment during periodontal wound healing in dogs. $J$ Periodont Res 1989;24:247-253.

13. Tal H, Pitaru S. Formation of new periodontal attachment apparatus after experimental root isolation with collagen membranes in the dog. Int J Periodontics Restorative Dent 1992;12:231-242.

14. Wang HL, O'Neal RB, Thomas CL, et al. Evaluation of an absorbable collagen membrane in treating Class II furcation defects. $J$ Periodontol 1994;65:1029-1036.

15. Anderegg CR, Martin SJ, Gray JL, Mellonig JT, Gher ME. Clinical evaluation of the use of decalcified freeze-dried bone allograft with guided tissue regeneration in the treatment of molar furcation invasions. J Periodontol 1991;62:264-268.

16. Lekovic V, Kenney EB, Carranza FJ, Danilovic V. Treatment of Class II furcation defects using porous hydroxylapatite in conjunction with a polytetrafluoroethylene membrane. J Periodontol 1990;61:575-578.

17. Schallhorn RG, McClain PK. Combined osseous composite grafting, root conditioning, and guided tissue regeneration. Int $J$ Periodontics Restorative Dent 1988;8(4):8-31.

18. Blumenthal $\mathrm{N}$, Sabe $\mathrm{T}, \mathrm{Barrington} \mathrm{E}$. Healing responses to grafting of combined collagen-decalcified bone in periodontal defects in dogs. J Periodontol 1986;57:84-90.

19. Nery EB, Eslami A, Van SR. Biphasic calcium phosphate ceramic combined with fibrillar collagen with and without citric acid conditioning in the treatment of periodontal osseous defects. J Periodontol 1990;61:166-172.

20. Blumenthal NM. The effect of supracrestal tricalcium phosphate ceramic-microfibrillar collagen grafting on postsurgical soft tissue levels. J Periodontol 1988;59:18-22.

21. Blumenthal N, Steinberg J. The use of collagen membrane barriers in conjunction with combined demineralized bone-collagen gel implants in human infrabony defects. J Periodontol 1990;61:319-327.

22. Garrett S, Loos B, Chamberlain D, Egelberg J. Treatment of intraosseous periodontal defects with a combined adjunctive therapy of citric acid conditioning, bone grafting, and placement of collagenous membranes. J Clin Periodontol 1988;15:383-389.

23. 'Caffesse RG, Nasjleti CE, Plotzke AE, Anderson GB, Morrison EC.
Guided tissue regeneration and bone grafts in the treatment of furcation defects. J Periodontol 1993;1145-1153.

24. Becker W, Lynch SE, Lekholm U, et al. A comparison of ePTFE membranes alone or in combination with platelet-derived growth factors and insulin-like growth factor-I or demineralized freeze-dried bone in promoting bone formation around immediate extraction socket implants. J Periodontol 1992;63:929-940.

25. Miller PO. Textbook of Periodontia. Philadelphia: The Blakeston Co.; 1938:91.

26. Löe H, Silness J. Periodontal disease in pregnancy. I. Prevalence and severity. Acta Odontol Scand 1963;21:533-551.

27. Silness P, Löe J. Periodontal disease in pregnancy. II. Correlation between oral hygiene and periodontal condition. Acta Odontol Scand 1964;22:121-135.

28. Nyman S, Gottlow J, Karring T, Lindhe J. The regenerative potential of the periodontal ligament. An experimental study in the monkey. $J$ Clin Periodontol 1982;9:257-265.

29. Nyman S, Lindhe J, Karring T, Rylander H. New attachment following surgical treatment of human periodontal disease. $J$ Clin Periodontol 1982;9:290-296.

30. Copperman L, Machaeli D. The immuno-genicity of injectable collagen I. A 1-year prospective study. J Am Acad Dermatol 1984;10: 638-646.

31. Quteish D, Singrao S, Dolby AE. Light and electron microscopic evaluation of biocompatibility, resorption and penetration characteristics of human collagen graft material. J Clin Periodontol 1991;18: 305-311.

32. Urist MR, Jurist JJ, Dubuc FL, Strates BS. Quantitation of new bone formation in intramuscular implants of bone matrix in rabbits. Clin Orthop 1970;68:279-293.

33. McClain PK, Schallhorn RG. Long-term assessment of combined osseous composite grafting, root conditioning, and guided tissue regeneration. Int J Periodontics Restorative Dent 1993;13:9-27.

34. Guillemin MR, Mellonig JT, Brunsvold MA. Healing in periodontal defects treated by decalcified freeze-dried bone allografts in combination with ePTFE membranes (I). Clinical and scanning electron microscope analysis. J Clin Periodontol 1993;20:528-536.

35. Becker W, Becker BE, Berg L, Prichard J, Caffesse R, Rosenberg E. New attachment after treatment with root isolation procedures: report for treated Class III and Class II furcations and vertical osseous defects. Int J Periodontics Restorative Dent 1988;8(3):8-23.

36. Wallace SC, Gellin RG, Miller MC, Mishkin DJ. Guided tissue regeneration with and without decalcified freeze-dried bone in mandibular Class II furcation invasions. J Periodontol 1994;65:244-254.

37. Schultz AJ, Gager AH. Guided tissue regeneration using an absorbable membrane (polyglactin 910) and osseous grafting. Int J Periodontics Restorative Dent 1990;10:8-17.

38. Gager AH, Schultz AJ. Treatment of periodontal defects with an absorbable membrane (polyglactin 910) with and without osseous grafting: Case reports. J Periodontol 1991;62:276-283.

39. Becker W, Becker BE, Caffesse R. A comparison of demineralized freeze-dried bone and autologous bone to induce bone formation in humanextraction sockets. J Periodontol 1994;65:1128-1133.

40. Rummelhart JM, Mellonig JT, Gray JL, Towle HJ. A comparison of freeze-dried bone allograft and demineralized freeze-dried bone allograft in human periodontal osseous defects. $J$ Periodontol 1989;60:655-663.

41. Mellonig JT. Decalcified freeze-dried bone allograft as an implant material in human periodontal defects. Int J Periodontics Restorative Dent 1984;4(6):40-55.

42. Altiere ET, Reeve CM, Sheridan PJ. Lyophilized bone allografts in periodontal intraosseous defects. $J$ Periodontol 1979;50:510-519.

43. Wood DL, Hoag PM, Donnenfeld OW, Rosenfeld LD. Alveolar crest reduction following full and partial thickness flaps. $J$ Periodontol 1972;43:141-144.

44. Lekovic V, Kenney EB, Kovacevic K, Carranza FJ. Evaluation of 
guided tissue regeneration in Class II furcation defects. A clinical re-entry study. J Periodontol 1989;60:694-698.

45. Pontoriero R, Lindhe J, Nyman S, Karring T, Rosenberg E, Sanavi F. Guided tissue regeneration in degree II furcation-involved mandibular molars. A clinical study. J Clin Periodontol 1988;15:247254.
Send reprint requests to: Dr. Hom-Lay Wang, University of Michigan, School of Dentistry, 1011 N. University Ave., Ann Arbor, MI 481091078.

Accepted for publication March 9, 1995. 